\title{
RELAÇÕES ENTRE POLÍTICA E RELIGIÃO NA DEFESA DE UMA EDUCAÇÃO "NEUTRA"
}

\author{
Karina Veiga Mottin (UFPR)* \\ https://orcid.org/0000-0002-2431-9599
}

\section{RESUMO}

A luta encampada contra a chamada "ideologia de gênero", impulsionada principalmente após as discussões e aprovações dos Planos de Educação em 2014 e 2015, é uma das facetas do Movimento Escola Sem Partido (MESP) e é central para a militância conservadora cristã no Brasil. Para contribuir com este debate, este artigo pretende discutir as relações entre política e religião no caso da batalha contra a palavra "gênero" no Plano Estadual de Educação do Paraná. Na primeira parte, discuto a laicidade do Estado, refletindo sobre este conceito à luz dos estudos do sociólogo Antônio Flávio Pierucci e das(os) antropólogas(os) Paula Montero e Emerson Giumbelli. Na segunda parte, analiso o uso de argumentos jurídicos para defender pautas religiosas, focando especificamente no caso da discussão do Plano Estadual de Educação do Paraná. Por fim, problematizo a ausência da palavra "gênero" neste documento como parte de uma cruzada contra as pautas que envolvem esse campo de estudos.

Palavras-chave: Religião. Política. Ideologia de gênero. Movimento Escola Sem Partido.

\section{ABSTRACT}

\section{RELATIONS BETWEEN POLITICS AND RELIGION IN DEFENSE OF A "NEUTRAL" EDUCATION}

The struggle against the so-called "gender ideology", driven mainly after the discussions and approvals of the Education Plans in 2014 and 2015, is one of the facets of the "Escola Sem Partido" Movement (MESP) and is central to the conservative Christian militancy in Brazil. To contribute to this debate, this article aims to discuss the relationship between politics and religion in the case of the battle against the word "gender" in the Paraná State Education Plan. First, I discuss the secularity of the State, reflecting on this concept in the light of the studies of the sociologist Antônio Flávio Pierucci and the anthropologists Paula Montero and Emerson Giumbelli. In the second part, I analyze the use of legal

Doutoranda em Educação pela Universidade Federal do Paraná (UFPR). Pesquisadora do Laboratório de Investigação de Corpo, Gênero e Subjetividades na Educação (LABIN/UFPR). E-mail: karimottin@gmail.com 
arguments to defend religious agendas, focusing specifically on the case of the discussion of the Paraná State Education Plan. Finally, I question the absence of the word "gender" in this document as part of a crusade against the guidelines that involve this field of study.

Keywords: Religion. Politics. Gender ideology. Escola Sem Partido Movement.

\section{RESUMEN}

\section{RELACIONES ENTRE POLÍTICA Y RELIGION EN DEFENSA DE UNA EDUCACIÓN "NEUTRA"}

La lucha contra la llamada "ideología de género", impulsada después de las discusiones y aprobaciones de los Planes de Educación en 2014 y 2015, es una de las facetas del Movimiento Escola Sem Partido (MESP) y es esencial para la militancia cristiana conservadora en Brasil. Para contribuir a este debate, este artículo tiene como objetivo discutir la relación entre política y religión en el caso de la lucha contra la palabra "género" en el Plan de Educación del Estado de Paraná. Primero, discuto la secularidad del Estado, reflexionando sobre este concepto a la luz de los estudios del sociólogo Antônio Pierucci y de los antropólogos Paula Montero y Emerson Giumbelli. En segunda, analizo el uso de argumentos legales para defender las agendas religiosas, centrándome en el caso de la discusión del Plan de Educación del Estado de Paraná. Por fin, cuestiono la ausencia de la palabra "género" en este documento como parte de una cruzada contra las pautas que involucran este campo de estudios.

Palabras clave: Religion. Politica. Ideología de género. Escola Sem Partido Movimiento.

\section{Introdução}

A defesa de uma educação "neutra", sem "ideologia" ou "doutrinação", é pauta defendida não apenas por adeptos do Movimento Escola Sem Partido (MESP), mas também por políticas(os) ${ }^{1}$ atuantes no Congresso Nacional, nas Assembleias Legislativas e nas Câmaras Municipais espalhadas pelo país. Nem sempre essas/esses sujeitas(os) declaram-se apoiadores do projeto do MESP, mas certamente suas ações de alguma forma reverberam o discurso defendido por este movimento. A luta contra a chamada "ideologia de gênero" é uma dessas facetas. Desde a sua criação, em 2004, o objetivo principal do MESP sempre foi o combate

1 Com relação à flexão de gênero dos substantivos, optei pelo uso do feminino antecedendo o masculino, como forma de evidenciar e quebrar a tendência em generificar no masculino. à "doutrinação marxista” nas escolas, mas ao encampar a batalha contra o "gênero", este movimento ganhou maior visibilidade no cenário nacional (MIGUEL, 2016). Neste artigo, as análises serão voltadas para a contenção da pauta de gênero, no contexto da aprovação do Plano Estadual de Educação do Paraná. Mais especificamente, pretende-se discutir as relações entre política e religião, tendo como ponto de partida a atuação de parlamentares cristãs(ãos) que procuram assumir um discurso de neutralidade ao defender suas convicções nos debates que antecederam a aprovação desse documento.

Após calorosos debates que acabaram por retirar toda e qualquer menção à palavra "gênero" do Plano Nacional de Educação em 2014, no ano seguinte, Estados e Municípios de todo o país, em sua maioria, também retiraram tal 
palavra dos seus respectivos documentos. No Paraná, deputadas e deputados subiram ao púlpito da Assembleia Legislativa do Estado do Paraná (ALEP) para fazer uma defesa da retirada da pauta de gênero, da "família brasileira" e de uma educação "neutra". A chamada "ideologia de gênero" apareceu nos argumentos de militantes e/ou políticos para expressar a indignação desses sujeitos contra um suposto plano (que seria orquestrado pela Organização das Nações Unidas) para "destruir" a identidade, o binarismo de gênero, a família e, por conseguinte, a sociedade. As escolas estariam sendo usadas para uma tentativa em implementar tal "ideologia", 2 por isso a luta contra as discussões sobre gênero nos Planos de Educação passou a ser central nos discursos de políticas(os) conservadores.

Na primeira parte deste artigo pretendo discutir a laicidade do Estado, propondo uma reflexão sobre este conceito, à luz dos estudos do sociólogo Antônio Flávio Pierucci e das(os) antropóloga(os) Paula Montero e Emerson Giumbelli. De maneira sucinta, procuro também discutir o histórico da presença católica e evangélica na política brasileira nas últimas décadas. Na segunda parte do texto, analiso o uso de argumentos jurídicos para defender pautas religiosas, focando especificamente no caso da discussão do Plano Estadual de Educação do Paraná. Para sustentar esse argumento, trechos das falas de deputadas(os) da ALEP estão expostas ao longo deste trabalho, e podem ser acessadas na íntegra através de consulta ao site do governo do estado do Paraná (PARANÁ, 2015a; PARANÁ, 2015b). Outros documentos legislativos também são utilizados como complementares.

2 Em linhas gerais, esses argumentos aparecem em diferentes produções sobre a "ideologia de gênero". Cito três referências amplamente utilizadas no meio acadêmico para compreender a criação, o significado e a disseminação dessa expressão: a nota da Conferência Episcopal Peruana (1998), o livro The Gender Agenda, da jornalista norteamericana Dale O'Leary (1997), e o livro do advogado argentino Jorge Scala (2010), La ideología de género: o el género como herramienta de poder.
A laicidade do Estado, a atuação de católicas/os e evangélicas/os na política brasileira e a "ideologia de gênero"

Existe um provérbio na Bíblia Sagrada, 22:06 que diz: 'Instrui o menino no caminho em que deve andar e até quando ele envelhecer não se desviará dele.' (PARANÁ, 2015b, p. 9).

Essa frase, proferida pela deputada Cantora Mara Lima (PSDB) na Assembleia Legislativa do Estado do Paraná (ALEP), poderia ter sido dita por quase todas(os) (senão todas(os)) as/os parlamentares que subiram ao púlpito para defender a retirada da palavra gênero do Plano Estadual de Educação. Mara Lima é conhecida pela sua carreira de cantora gospel e é membro da Igreja Assembleia de Deus há mais de 35 anos (DEPUTADA ESTADUAL CANTORA MARA LIMA, 2018). A deputada não é a única parlamentar conhecida pela comunidade cristã na ALEP. 0 deputado Pastor Edson Praczyk (PRB) é membro da Igreja Universal do Reino de Deus desde 1981 e pastor desde 1995 (PASTOR EDSON, 2018). A deputada Cláudia Pereira (PSC), que compõe a Comissão de Constituição e Justiça da ALEP (responsável pela modificação que retirou a palavra gênero do PEE do Paraná), é membro da Congregação Cristã no Brasil (ASSEMBLEIA LEGISLATIVA DO ESTADO DO PARANÁ, 2015). 0 deputado Gilson de Souza (PSC) também é pastor da Igreja do Evangelho Quadrangular há mais de 30 anos (ASSEMBLEIA LEGISLATIVA DO ESTADO DO PARANÁ, 2018). Assim como estes, que declaradamente lutam contra a "ideologia de gênero", a grande maioria das(os) parlamentares, quando tiveram a palavra no dia 17 ou no dia 22 de junho de 2015 (datas em que foram votadas a legalidade e a aprovação do Plano Estadual de Educação - PEE do Estado do Paraná), demonstraram seu comprometimento com as/os cristãs(ãos), cumprimentando-as/ 
os, assim como o deputado Gilson de Souza (PSC): "[...] os amigos, amigas que ocupam as galerias, neste momento, Pastores, Padres, líderes evangélicos, cristãos, queremos dar as boas-vindas a todos" (PARANÁ, 2015b, p. 6), ou mencionando um simples "Deus abençoe a todos” (PARANÁ, 2015a, 2015b).

A constatação acima, feita a partir da leitura dos Diários Oficiais, que trazem a transcrição destes debates (PARANÁ, 2015a, 2015b), pode gerar diversas reflexões. A mais imediata é que a religião, de alguma forma (ou de várias formas), está presente na política. Mais ainda, está "interferindo" nas decisões políticas. Partindo desse viés, seria possível criticar a postura das(os) deputadas(os), reforçar que seus posicionamentos são um ataque à laicidade do Estado e até mesmo postular ações a serem implementadas com o objetivo de alcançar uma laicidade plena, se isso fosse possível. Contudo, se o trabalho de pesquisa terminasse com essa postura, ficariam para trás possibilidades de reflexão sobre a complexidade dos fatos. Por isso, mostra-se potencialmente mais explicativo pensar nos processos que culminaram no contexto analisado. Nesse sentido, o esforço é para investigar "como" estas/estes personagens se colocam na esfera política e quais estratégias elas/eles utilizaram para traduzir pautas religiosas em pautas sociais (MONTERO, 2012).

Quando o assunto é a relação entre política e religião, inevitavelmente nos deparamos com os conceitos de laicidade e/ou de secularização. Ambos se referem à separação entre Igreja e Estado, geralmente o primeiro termo tem uma conotação ideológica (no sentido de "ideal" a ser seguido, sistema de ideias que orientam uma ação), enquanto o segundo tem sido utilizado frequentemente para pensar os processos de separação entre Igreja e Estado. ${ }^{3}$

3 Emerson Giumbelli faz uma discussão sobre a distinção e o uso dos conceitos de secularismo e laicidade em diferentes estudos, porém, neste artigo, não cabe aprofundar a crítica a estes termos. 0 conceito de secularismo é abordado nessa pesquisa para pensar a influência do paradigma weberiano da secularização nos estudos sobre as relações entre política e religião. Já a laicidade é trazida para deslocar o
A discussão acerca do paradigma weberiano da secularização é profícua para as pesquisas que abordam os temas "gênero", "religião" e "política", uma vez que há uma tendência em assumir a premissa de que um espaço democrático constitui-se sobre a exclusão das religiões e/ou seus representantes. Essa ideia remete ao chamado "paradigma weberiano da secularização", que em linhas gerais pressupõe que quanto mais um Estado está afastado da religião, mais democrático, ou ainda, mais "civilizado" ele é. Ou seja, nesta leitura vulgarizada da obra de Max Weber, a laicidade passa a ser compreendida como a "eliminação" da religião da esfera pública e torna-se um "ideal" a ser alcançado. Essa forma de pensar carrega consigo alguns problemas.

0 primeiro problema que surge ao assumir essa leitura da teoria weberiana é que essa interpretação já foi amplamente problematizada por sociólogos e antropólogos da religião, que apontaram que essa é uma leitura tendenciosa e pouco precisa da obra de Max Weber. Segundo Antônio Flávio Pierucci (1998), “[...] Weber, em sua sociologia, constatou, mais do que pensou, o retraimento da religião na razão direta do avanço da modernização capitalista." (PIERUCCI, 1998, p. 45). Isso significa que, na mesma medida em que a sociedade ocidental se aproximava da modernidade, ela também se afastava da religião. Esse contexto de secularização constatado por Weber referia-se especificamente à Europa do final do século XIX e começo do XX, período marcado pelo apogeu da racionalidade e pelo retraimento das religiões em força e importância no mundo ocidental, em especial a Igreja Católica, que perdia poder e prestígio com sua separação do Estado.

O discurso sobre a secularização da Europa era também sobre a alteridade europeia: essa sociedade descolava-se cada vez mais do controle das autoridades eclesiásticas e

foco da análise, substituindo a negatividade do termo pela sua produtividade ou configuração (como será exposto na sequência). Para aprofundar o conhecimento sobre a diferença entre secularização e laicidade, ver Giumbelli (2013b). 
criava uma imagem de si construída sobre o discurso da ciência e do direito, afastando-se das sociedades ditas "não modernas", supostamente aprisionadas por mitos e magias (MONTERO, 2012). Entretanto, a afirmação de que a secularização seria o destino final das sociedades modernas e a consequente conclusão de que sociedades menos secularizadas seriam, portanto, menos "civilizadas", não é algo que o sociólogo tenha afirmado. Pierucci e Montero criticam essa interpretação da teoria weberiana:

Atribuem a Weber, à sua revelia, um prognóstico fechado de definhamento da religião na sociedade moderna na razão direta do avanço linear da racionalidade formal-instrumental, profecia que, entretanto, não se cumpriu. Como se Weber não costumasse escarnecer das profecias acadêmicas [...] (PIERUCCI, 1998, p. 47).

[...] o paradigma weberiano da secularização ainda orienta demasiadamente as análises mais sociológicas fazendo com que se percebam as religiões, no melhor dos casos, como um instrumento para o aprendizado da modernização em sociedades que não passaram pela revolução burguesa, e, no pior, como um obstáculo à democracia a ser erradicado. (MONTERO, 2012, p. 168).

Pierucci (1998) ressalta que pelo menos nas três últimas décadas do século XX, ao contrário do que era professado pelos entusiastas do paradigma weberiano, houve um reavivamento das religiões no Ocidente, que visivelmente se expandiram e multiplicaram. Mais ainda, o sociólogo reitera que no "terceiro mundo", na "periferia do capitalismo", o processo de desencantamento do mundo ${ }^{4}$ ocorreu de maneira

4 Sobre a distinção dos conceitos de racionalização, desencantamento do mundo e secularização na obra de Max Weber: "Em Weber, o processo de racionalização é mais amplo e mais abrangente que o desencantamento do mundo e, neste sentido, o abarca; o desencantamento do mundo, por sua vez, tem a duração histórica mais longa, mais extensa que a secularização e, neste sentido, a compreende. 0 importante a reter é que Weber realmente distingue os diferentes processos. Enquanto o desencantamento do mundo fala da ancestral luta da religião contra a magia, sendo uma de suas manifestações mais recorrentes e eficazes a perseguição aos feiticeiros e bruxas [...], a secularização, por sua vez, nos remete à luta da modernidade cultural contra a religião, tendo como bem diferente do europeu (PIERUCCI, 1998). Neste ponto, surge o segundo problema em assumir o ponto de vista do paradigma weberiano da secularização. Visto que as análises de Weber se referiam especificamente à Europa do século XIX, certamente a tentativa de aplicação no contexto brasileiro de um suposto ideal de democracia ou modernidade (ou qualquer outro) formulado no e para o contexto europeu seria fracassada.

Além disso, como ressalta Montero (2012), o processo de separação entre a Igreja Católica e o Estado brasileiro teve suas peculiaridades. Aqui, as agências religiosas tiveram um papel importante na construção da sociedade civil separada da religião, ou seja, o processo de secularização foi também produto do próprio trabalho religioso. Para Montero (2012), é preciso reconhecer o papel da Igreja Católica na formulação de uma ideia de direitos e na construção da sociedade civil brasileira, em pelo menos três momentos: a) A Igreja Católica participou do debate sobre a laicização do Estado na 1ํㅡㄹ República: "ao ser expulsa, contra a sua vontade, do aparato estatal, a Igreja Católica tornou-se uma força política, entre outras, dessa esfera civil em construção" (MONTERO, 2012, p. 170). Por exemplo, exercendo um importante papel na reivindicação de liberdade religiosa, que foi garantida pela Constituição de 1891; b) Durante a ditadura militar no Brasil (1964-1985), várias lideranças religiosas ligadas à "teologia da libertação" desempenharam um importante papel na formação de movimentos sociais de base; e c) A partir do final da década de 1980, religiosos católicos ligados à "teologia da inculturação" tiveram importante atuação na defesa de direitos culturais de minorias étnicas, como no caso de indígenas e outras populações tradicionais.

Desse modo, permanece como questão para nossa agenda de pesquisa como as categorias religiosas de longa duração tais como direito

manifestação empírica no mundo moderno o declínio da religião como potência in temporalibus, seu disestablishment (vale dizer, sua separação do Estado) [...]" (PIERUCCI, 1998, p. 52, grifo do autor). 
natural, comunidade, participação, justiça etc. imantaram e se combinaram a outras tradições políticas de modo a constituir nossa visão de sociedade democrática. [...] Além disso, grande parte das categorias utilizadas na mobilização política e seus estilos de organização também podem ser considerados tributários do modelo de organização da Igreja Católica que, a partir dos anos 1970, inspirou e apoiou vários movimentos que deram origem e visibilidade ao que a literatura alcunhou de 'sociedade civil'. Basta observar como categorias do tipo 'pobre', 'comunidade', 'caminhada', 'libertação', 'fraternidade' etc., circulam até hoje no campo dos movimentos sociais para nos darmos conta da força persuasiva desse modelo. (MONTERO, 2012, p. 171, grifo do autor).

Outros exemplos são utilizados pela antropóloga para demonstrar como as religiões não migraram do espaço público para o privado, a saber: a concessão pública de canais televisivos e de radiodifusão a confissões religiosas; e a atuação das bancadas religiosas no Congresso Nacional, nas Assembleias Legislativas e Câmaras de Vereadores em todo o país (MONTERO, 2012). Muitas vezes, as religiões ressignificam categorias políticas como "direito" e "igualdade" para introduzir no debate político valores religiosos, assim como têm a habilidade de mobilizar grupos sociais em torno de determinadas causas. Ou seja, o desafio está em esmiuçar a complexidade das relações entre religião e política.

Após ter especificado algumas das particularidades das relações entre religião e Estado no caso brasileiro, pode-se avançar para o terceiro problema que surge ao se tentar alcançar um estágio no qual a religião não teria influência alguma sobre a política. 0 problema é que esse ideal é inatingível e, por isso, pouco eficaz para ser utilizado nesta pesquisa. Desde fins do século XX anunciava-se a necessidade de renovação dos estudos da religião, de reconhecimento da complexidade da relação entre Igreja e Estado, religião e política, das fronteiras entre religião no espaço privado e público. Sociólogas(os) da religião e antropólogas(os) culturais vêm demonstrando que é ineficaz pensar a secularização como uma luta para expurgar a religião do Estado ou dos espaços públicos.

O propósito é passar a fazer uma sociologia que reconheça a capacidade demonstrada pela religião de resistir ao ataque serrado da modernidade. Hoje, enquanto a modernidade faz água, volta à tona, revigorada, a religião. $\mathrm{E}$ junto com ela emerge, em certos círculos de sociólogos, a demanda por uma nova sociologia da religião. Menos injusta com seu pulsante objeto. Menos preconceituosa com o sagrado. (PIERUCCI, 1998, p. 43-44).

Nessa mesma linha de reflexão, Emerson Giumbelli (2013a) aponta que o uso do termo "laicidade" por cientistas sociais usualmente tem duas conotações: às vezes é entendido como uma ideologia ou um posicionamento no que se refere ao lugar da religião na esfera pública; outras vezes é entendido como a configuração das relações entre o Estado (ou espaços públicos) e agentes religiosas(os), entre estas/estes e a população, ou ainda entre as/os agentes religiosas(os) entre si. Nesses dois casos, a laicidade é compreendida como uma limitação, definindo quais ações não são permitidas na esfera pública ou estatal. Esse autor propõe que ao invés de caracterizar o que a laicidade deve evitar, o que "não pode" acontecer em um Estado laico, pensemos o inverso, em "como" a laicidade pode funcionar ou se constituir. Giumbelli (2013b) afirma que o uso do termo laicidades, no plural, por parte da literatura sobre religião, indica a recusa de modelos ideais e sugere que tais pesquisas têm maior disposição comparativa. Parte-se do pressuposto de que não é possível impedir a participação de sujeitos que são engajados em determinada religião na esfera pública, nem mesmo mensurar em que medida as crenças religiosas influenciam nas tomadas de decisões. Sendo assim, a questão colocada pelo antropólogo: “o que é um ambiente laico?" é pertinente não apenas para pensar a materialidade das religiões em espaços públicos ou estatais, mas também com relação à presença de atrizes/ atores religiosas(os) na cena política, como é o 
caso desta pesquisa. 0 antropólogo sugere que o nosso desafio está justamente na constante caracterização do que significa ser "laico", pois "as instituições continuarão envolvidas com a gestão do religioso" (GIUMBELLI, 2013a, p. 44, grifo do autor).

No caso brasileiro, atualmente destacam-se a presença de parlamentares cristãos atuantes principalmente nas igrejas católica e evangélicas. As relações entre estas denominações religiosas são mais complexas do que apenas a disputa ou a aliança sobre determinadas pautas. Há que se considerar o histórico da atuação política das religiões, portanto, na sequência será discutida brevemente a participação de militantes religiosos no espaço público.

Como ponto de partida é importante problematizar a hegemonia do catolicismo no Brasil, expressa tanto pela sua importante participação no processo de secularização, quanto pela sua influência na formação da identidade brasileira (cultural, religiosa e mesmo educacional). Roney Polato de Castro (2017, p. 82) aponta a religião como um elemento constituinte da identidade histórica de brasileiras(os): "A religião é uma característica que nos constitui enquanto brasileiros, marcada por nossa tradição histórica e forte poder exercido especialmente pela Igreja Católica." Esse fator é expresso em entrevistas feitas pelo autor com professoras de duas escolas públicas (uma municipal e outra estadual) de Juiz de Fora. A maioria das professoras(es), mesmo as/os que professam outras religiões na atualidade ou se denominam "não praticantes", afirmou ter formação católica. Para esse autor, essa é uma formação religiosa que deixa marcas nos modos de agir e, por isso, não pode ser ignorada. "Os valores religiosos estão na base das relações sociais, especialmente nas relações familiares, algo que reverbera na formação dos sujeitos de modo heterogêneo." (CASTRO, 2017, p. 83).

No entanto, essa presença e influência do catolicismo na história e na formação da identidade brasileira, muitas vezes, torna essa religião "invisível" nos espaços públicos. $\mathrm{Na}$ política não é diferente, como afirma Montero (2012, p. 171-172):

Quando se faz uma análise comparativa entre a Igreja Católica e outras instituições religiosas na sua capacidade de influir e pautar a agenda política, é possível afirmar que permanece uma desigualdade estrutural, histórica, na percepção que se tem a respeito da legitimidade da ação das diferentes religiões na esfera pública. 0 catolicismo ainda mantém, a meu ver, a primazia simbólica e política na passagem dos valores para as normas. [...] 0 protestantismo pentecostal nos parece ser hoje o único grande movimento religioso que, pelo seu rápido crescimento e progressiva conquista de meios de produção de visibilidade tais como canais de rádio e televisão, desafia essa hegemonia.

Ou seja, atualmente testemunhamos o crescimento do protestantismo pentecostal e não pentecostal, aqui generalizados como "evangélicas(os)", 5 que avança na cena política. Ao mesmo tempo que as/os evangélicas(os) aliam-se às/aos católicas(os), abraçando pautas historicamente por elas/eles defendidas (como a oposição ao aborto e às pesquisas com células-tronco), elas/eles também tomam o protagonismo frente a estas questões, ameaçando a hegemonia católica.

Esse é o caso das narrativas sobre a "ideologia de gênero". É praticamente consenso entre as/os pesquisadoras(es) que se dedicam a estudar a emergência da "ideologia de gênero", que a expressão provém da atuação de membros da alta cúpula do catolicismo. Rogério Diniz Junqueira (2017, p. 26) afirma que a "ideologia de gênero" é "uma invenção católica que emergiu sob os desígnios do Conselho Pontifício para a Família e de conferências episcopais, entre meados da década de 1990 e no início dos 2000". A nota da Conferência Episcopal Peruana (1998) é amplamente referenciada por pesquisadoras(es) como a

5 A denominação "evangélicas(os)" é utilizada para referir-se religiões pentecostais e não pentecostais. Essa classificação segue a generalização feita pelo Censo Demográfico e pela literatura das ciências sociais da religião, que pontua as diferenças internas entre cada denominação, mas serve-se da categoria geral para análises mais amplas, como é o caso desta pesquisa (ALMEIDA, 2017). 
primeira aparição do termo em documentos oficiais da Igreja católica. Todavia, como bem apontam Amanda da Silva e Maria Rita de Assis César (2017), os temas presentes na nota da Conferência Episcopal do Peru são recorrentes em documentos produzidos pela Igreja tanto décadas antes desta nota, quanto depois dela. Junqueira (2017) também cita outros documentos católicos que utilizaram a expressão posteriormente e destaca a atuação de Joseph Aloisius Ratzinger antes e também durante o período de seu papado (2005-2013) na "viralização" do termo, que passou a ser utilizado em um movimento transnacional antigênero.

No entanto, apesar de a "ideologia de gênero" ter sido produzida e insistentemente disseminada pelas(os) católicas(os), as/os evangélicas(os) não apenas abraçaram a causa como em muitos casos tomaram o protagonismo nesta luta. 0 atual empenho das(os) evangélicas(os) é tamanho, produzindo conteúdos na internet ou em bancadas legislativas, que em diversos contextos invisibiliza a atuação católica. Isso não significa que as/os católicas(os) estejam menos atuantes ou que em alguns contextos elas/eles continuem se sobressaindo, como mostram, por exemplo, as pesquisas de Myrim Aldana Vargas, Murilo Cavagnoli e Daian Cattani (2016) sobre o PME de Chapecó (SC), e de Amanda Ribeiro, Cristina Satiê de Oliveira Pátaro e Frank Antonio Mezzomo (2016) sobre o PME de Campo Mourão (PR). Contudo, no caso do objeto de investigação deste artigo, as narrativas que embasaram a retirada da palavra gênero do PEE do Paraná, o movimento foi protagonizado pelas(os) evangélicas(os), como demonstra a descrição do histórico religioso de membros da ALEP no início deste artigo.

Em 2015, na ocasião da aprovação do PEE do Paraná, das(os) 54 deputadas(os) estaduais que compunham a ALEP (4 mulheres e 50 homens), 8 faziam parte da bancada evangélica. É visível o crescimento desse grupo na política, nas câmaras municipais, nas assembleias legislativas ou na câmara das(os) deputadas(os). ${ }^{6}$
As/os evangélicas(os) unem-se a outros grupos para defender seus interesses e dessa forma aumentam sua força política. ${ }^{7}$ No entanto, não se pode homogeneizar a atuação política das(os) evangélicas(os), pois nem todas(os), sejam políticas(os) ou não, são unânimes na defesa de pautas conservadoras. ${ }^{8}$ Sandra Duarte de Souza (2017) alerta que as denominações "evangélicas(os)" ou "católicas(os)" evocam um sujeito coletivo que oculta as dissonâncias presentes nas próprias instituições religiosas. Sua pesquisa sobre a atuação de deputadas que compõem as bancadas Católica e Evangélica no Congresso Nacional ${ }^{9}$ frente aos projetos que se referem aos direitos da população LGBT $^{10}$ constatou que a maioria das mulheres que compunham as duas bancadas religiosas (na 55 ${ }^{\text {a }}$ legislatura) não assinaram qualquer

Assessoria Parlamentar (DIAP) mostra o crescimento no Congresso Nacional: em 2018 foram eleitas(os) ou reeleitas(os) 84 deputadas(os); em 2014 eram 75 deputadas(os); e em 2010, as/os evangélicas(os) contavam com 73 representantes (NASSIF, 2018).

7 É o caso da união de três grupos na chamada "bancada BBB": Boi - ruralistas, defensoras(es) do agronegócio -; Bala - policiais e militares, que defendem o endurecimento da legislação para punir qualquer tipo de crime e defendem a revogação do Estatuto do Desarmamento; e Bíblia bancada evangélica (CUNHA, 2017).

8 Ao analisar a presença das(os) evangélicas(os) na esfera política no Brasil, o antropólogo Ronaldo de Almeida (2017) chama atenção para a complexidade da definição do que é conservadorismo. Por exemplo, a defesa da pena de morte poderia ser um indicador, mas não se aplica às/aos evangélicas(os), que em sua maioria são contra ela. Ainda assim, Almeida (2017) aponta alguns pontos em comum nesses diversos grupos conservadores. São eles: a celebração do esforço e do mérito individual (na economia); defesa da repressão e punição, apoiando pautas como a redução da maioridade penal e maior militarização da gestão pública; intolerância interpessoal no que se refere a temas políticos e morais; e, por fim, contenção e restrição no campo da moralidade liberal e laica, atuando a favor de maior regulação de comportamentos sexuais e dos corpos (incluindo pesquisas genéticas) e de vínculos primários (como casamento e adoção por casais LGBT).

9 Frente Parlamentar Mista Católica Apostólica Romana (FPMCAR) e Frente Parlamentar Evangélica (FPE).

10 Existem algumas variações de siglas utilizadas pelas organizações que defendem os direitos da população LGBT, dentre elas: LGBTI, LGBTQ LGBTPQIA, algumas com o uso do sinal + para representar identidades que possivelmente não estariam contempladas. Mesmo considerando que a sigla LGBT não engloba a totalidade da população que se identifica com ou milita neste movimento, optei pelo seu uso neste artigo por ser a sigla mais utilizada, inclusive oficialmente, por organizações internacionais que atuam em prol dos direitos humanos, como a ONU e a Anistia Internacional. 
projeto em apoio às demandas LGBT, mas também não assinaram os projetos contra. O posicionamento "neutro" foi assumido por todas as deputadas que se declaram católicas e por nove das quinze deputadas que são parte da Frente Parlamentar Evangélica. Portanto, Souza (2017, p. 72) conclui que:

Parece haver dissonâncias entre uma parcela das mulheres que compõem as bancadas católica e evangélica e sua orientação moralista. Os motivos ainda precisam ser investigados, mas esse quadro sugere haverem fissuras nas aparentemente sólidas e impermeáveis estruturas da Frente Parlamentar Mista Católica Apostólica Romana e da Frente Parlamentar Evangélica.

É possível afirmar, portanto, que há disputas e divergências tanto dentro de cada denominação religiosa, quanto fora, entre as religiões, nesse caso, católica e evangélica. Ainda assim, no cenário brasileiro, sobretudo na política, é que as diferenças se reduzem e "é na sua militância contra a ampliação de direitos reprodutivos e sexuais de mulheres e LGBTs, e pelo retrocesso em relação a direitos já adquiridos por esses grupos, que tais diferenças praticamente desaparecem" (SOUZA, 2017, p. 57).

A tarefa que está posta, portanto, é a tentativa de compreender e analisar as estratégias utilizadas pelas(os) parlamentares cristãs(ãos) para impulsionar suas pautas. No caso do objeto de estudo deste trabalho, os argumentos utilizados por deputadas e deputados da ALEP para retirar a palavra "gênero" do Plano Estadual de Educação do Paraná, ocorre uma transformação de pautas de fundo religioso em pautas sociais. Diversos pesquisadores têm demonstrado que essa estratégia tem sido recorrentemente empregada por militantes religiosos para defender suas pautas. ${ }^{11}$

11 Além das pesquisas já mencionadas de Giumbelli (2013a; 2013b) e Montero (2012), destaco a pesquisa de Naara Luna (2017), que analisa o uso de argumentos que apelam para o direito e para a ciência, que deputadas(os) utilizaram ao longo do ano de 2015 para se posicionar contra o aborto, a criminalização da homofobia, o reconhecimento institucional da identidade de gênero, e também a "ideologia de gênero". A pesquisa de Souza (2017) também destaca que deputadas(os) federais da 55 Legislatura utilizaram argumentos pretensamente científicos ou
Nas próximas páginas será analisado o uso de argumentos jurídicos, ou seja, as formas com que a legislação vigente é utilizada pelas(os) parlamentares para sustentar a defesa de pautas religiosas.

\section{0 argumento jurídico: "em defesa da Constituição Brasileira, votamos contra a ideologia de gênero"}

\begin{abstract}
Deixemos as crianças serem crianças, as meninas serem meninas e os meninos serem meninos. [Manifestações nas galerias] Acreditamos que isto supera, isto ultrapassa a questão religiosa. Temos aqui várias denominações e temos pessoas que nem creem em Deus, mas acreditam na família, acreditam nessa instituição e estão favoráveis ao projeto como está hoje. (PARANÁ, 2015b, p. 18)
\end{abstract}

Nessa fala da Deputada Claudia Pereira (PSC), percebe-se que há um esforço em colocar a "ideologia de gênero" como pauta que está além da religião: "isto supera, isto ultrapassa a questão religiosa”. A pretensão de universalidade dos argumentos utilizados pela deputada está exposta também nas expressões "várias denominações" ou "pessoas que nem creem em Deus". Afinal, quem se manifestaria "contra" a "família"? A definição e a defesa do que é esta família, na perspectiva das(os) deputadas(os), é supostamente baseada em argumentos jurídicos, não religiosos. As palavras Lei, Direito e Constituição parecem ter um grande peso nesse debate. Estes foram pilares de sustentação para justificar a luta contra as pautas LGBT, que culminaram na retirada da palavra "gênero" no PEE do Paraná. A justificativa jurídica é utilizada pelas(os) parlamentares da ALEP basicamente de duas formas: a defesa da "Lei" ou apenas da Constituição Federal brasileira de 1988;

jurídicos para justificar seus posicionamentos contra a inserção da pauta de gênero nos Planos de Educação e contra o reconhecimento institucional da identidade de gênero. 
e o direito que a família, mães e pais, têm de educar suas/seus filhas(os) da maneira como entendem que é o melhor para elas/eles. Essas duas premissas, que se misturam e se reforçam, serão apresentadas neste texto, da forma como foram trazidas pelas deputadas e deputados.

O primeiro argumento jurídico - a "defesa" da Constituição Federal brasileira de 1988 ou apenas da "Lei" - é expressa de diferentes formas. Nas falas das(os) parlamentares há uma preocupação em destacar a legalidade de todo o processo de aprovação do PEE do Paraná. Tal preocupação pode ser um reflexo dos questionamentos e manifestações de diversas entidades, associações de pesquisa e movimentos sociais sobre a retirada da pauta de gênero do documento. ${ }^{12}$ De fato, naquele mesmo ano, 2015, o Ministério da Educação, através de nota emitida pela Secretaria de Educação Continuada, Alfabetização, Diversidade e Inclusão (MINISTÉRIO DA EDUCAÇÃO, 2015a), reiterou a importância de incluir os conceitos de gênero e orientação sexual nos Planos de Educação. Também o Conselho Nacional de Educação (CNE) considerou que "a ausência ou insuficiência de tratamento das referidas singularidades [diversidade sexual e de gênero] fazem com que os planos de educação que assim as trataram sejam tidos como incompletos e que, por isso, devem ser objeto de revisão" (MINISTÉRIO DA EDUCAÇÃO, 2015b). Diante da dimensão desse embate, reforçar que o projeto do PEE do Paraná estava de acordo com a Lei era fundamental e, para este fim, discutiam as/os parlamentares no dia 17 de junho de 2015, cuja sessão terminou com a aprovação da legalidade do documento.

No que se refere à legalidade do documento, o ponto central na fala das(os) parlamentares é a afirmação de que "o projeto na CCJ foi corrigido pelas emendas e tornou-se constitucional" (PARANÁ, 2015a, p. 5), nas palavras do

12 Como a Associação Nacional de Pós-Graduação e Pesquisa em Educação (ANPEd), a Associação Brasileira de Ciência Política e a Associação Brasileira de Antropologia (VEIGA, 2015). presidente da ALEP, Ademar Traiano (PSDB). Ou seja, na visão das(os) parlamentares, a presença da palavra "gênero" no PEE do Paraná tornava-o inconstitucional. Essa afirmação é expressa, por exemplo, nas falas dos deputados Felipe Francischini (SD), Paranhos (PSC), Pastor Edson Praczyk (PRB) e Artagão Júnior (PMDB), na sequência transcritas:

0 projeto, como eu já disse, é totalmente constitucional, a partir do momento que a Deputada Claudia apresentou as emendas, porque a família, segundo o art. 226 da Constituição, é a base da sociedade, e o Estado merece prestar total atenção à família. (PARANÁ, 2015a, grifo nosso).

[...] e é evidente que este projeto é inconstitucional, porque ele fere a nossa Constituição onde diz: 'para efeito de proteção do Estado, é reconhecida a união estável entre homem e mulher como entidade familiar'. Esta é a decisão. (PARANÁ, 2015a, grifo nosso).

[...] porque ao meu ver, embasando-me pela Constituição do nosso país, família, indiscutivelmente, é composta por um homem e uma mulher. (Aplausos) Sendo assim, Sr. Presidente, o projeto originário tem um erro. Erro esse que foi corrigido oportunamente, de forma brilhante, pela Deputada Claudia Pereira, sanando assim a inconstitucionalidade do projeto. (PARANÁ, 2015a, grifo nosso).

[...] porque quando falamos da constitucionalidade e quando falamos no gênero da forma como foi apresentado, temos a mudança do conceito de família, e quando você apresenta um projeto mudando um conceito que tem a sua fundamentação na Constituição, esse projeto tem que ser entendido como inconstitucional. Por isso, a Deputada Claudia Pereira, com o apoio de diversos Parlamentares, como nossa Relatora e representando a Comissão de Justiça, fez a apresentação daquelas emendas que justamente traziam essa modificação. Portanto, Sr. Presidente, muito embora entendamos que da forma como foi apresentado esse projeto ele seria inconstitucional, porque muda o conceito constitucional da família, deixamos aqui o nosso posicionamento em defesa da família, apoiando as emendas apresentadas que serão votadas em segunda discussão. (PARANÁ, 2015a, grifo nosso). 
Os dois documentos nos quais estão presentes nas falas citadas dos deputados serão expostos na sequência. Primeiro, a Constituição Federal de 1988 - artigo 226 parágrafo terceiro -, utilizada para defender a inconstitucionalidade que a inserção da pauta de gênero traria ao PEE do Paraná:

Art. 226. A família, base da sociedade, tem especial proteção do Estado.

$\S 1$ o 0 casamento é civil e gratuita a celebração.

$\S 2^{\mathrm{o}} \mathrm{O}$ casamento religioso tem efeito civil, nos termos da lei.

\section{§ 3 Para efeito da proteção do Estado, é reconhecida a união estável entre o homem e a mulher como entidade familiar, devendo a lei facilitar sua conversão em casamento.}

$\S 4$ o Entende-se, também, como entidade familiar a comunidade formada por qualquer dos pais e seus descendentes.

$\S 5$ o 0 s direitos e deveres referentes à sociedade conjugal são exercidos igualmente pelo homem e pela mulher. [...]. (BRASIL, 1988, grifo nosso).

Cabe problematizar que qualquer documento ou legislação - inclusive a Constituição Federal de 1988 - precisa ser compreendido no contexto de sua produção, de acordo com valores, crenças e ponto de vista daqueles que idealizaram. Outro ponto que provoca reflexão é que a base jurídica pode oferecer sustentação tanto a argumentos que visam a manutenção de um certo ideal de família heteronormativa - como defendem os deputados -, quanto argumentos que pretendem abalar este ideal. ${ }^{13}$ Portanto, o que está em evidência não é a

13 Em outras palavras, a própria Constituição Federal de 1988 também oferece base jurídica para a defesa das famílias homoafetivas. A desembargadora do Tribunal de Justiça do Rio Grande do Sul, Maria Berenice Dias, argumenta que "Não há como afirmar que o art. 226, § 3º, da Constituição Federal, ao mencionar a união estável formada entre um homem e uma mulher, reconheceu somente essa convivência como digna da proteção do Estado. 0 que existe é uma simples recomendação em transformá-la em casamento. Em nenhum momento foi dito que não existem entidades familiares formadas por pessoas do mesmo sexo. Exigir a diferenciação de sexos no casal para haver a proteção do Estado é fazer 'distinção odiosa', postura nitidamente discriminatória que contraria o princípio da igualdade, ignorando a existência da vedação de diferenciar pessoas em razão de seu sexo (DIAS, 2009, p. 42).
Constituição Federal de 1988, sua defesa ou não, mas sim a manobra feita para defender um ideal cristão - a família heteronormativa - apoiando-se no peso e importância que este documento tem enquanto lei.

As falas das(os) deputadas(os) anteriormente explicitadas referem-se ao documento-base do PEE do Paraná, elaborado após as audiências públicas pelo Comitê Gestor. ${ }^{14}$ A seguir estão expostas as sete referências à palavra "gênero" que originalmente estavam presentes neste projeto:

- 1.3 Orientar as instituições educacionais que atendem crianças de zero a cinco anos a agregarem ou ampliarem, em suas práticas pedagógicas cotidianas, ações que visem ao enfrentamento da violência sexual e a outros tipos de violência, à inclusão e ao respeito às diversidades de toda ordem: gênero, étnico-racial, religião, entre outros, à promoção da saúde e dos cuidados, à convivência escolar saudável e ao estreitamento da relação família-criança-instituição. (AUTOR, ANO, p. 64, grifo nosso).

- 2.22 Assegurar que a Educação das Relações Étnico-Raciais, a Educação de Gênero e Sexualidade, o Ensino de História e Cultura Afro-Brasileira, Africana e Indígena e o Plano Nacional de Cidadania e Direitos Humanos LGBT sejam contemplados nos currículos da Educação Básica. (AUTOR, ANO, p. 67, grifo nosso).

3.22 Implementar políticas de prevenção à evasão motivada por preconceito de gênero, raça, orientação sexual, etnia ou quaisquer formas de discriminação, criando rede de proteção contra formas associadas de exclusão. (AUTOR, ANO, p. 70, grifo nosso).

7.32 Promover o acesso, a permanência e condições igualitárias de aprendizagem aos sujeitos das discussões de gênero e diversidade sexual, bem como a articulação entre as temáticas e conteúdos no currículo da Educação Básica. (AUTOR, ANO, p. 81, grifo nosso).

7.38 Estabelecer mecanismos de monitoramento dos casos de evasão, abandono, reprovação e aprovação por Conselho de Classe nas situações de preconceito e discriminação aos povos Roma-

140 Comitê Gestor foi composto por representantes de diversos setores da sociedade civil, segmentos educacionais e por onze instituições governamentais e não governamentais (PARANÁ, 2015d). 
ni (ciganos), sujeitos do campo, povos indígenas, população negra, LGBT e relações de gênero. (AUTOR, ANO, p. 81, grifo nosso).

15.6 Articular a estrutura curricular dos cursos de licenciatura com a base nacional comum dos currículos da Educação Básica, atendendo a diversidade de gênero e étnico-racial das comunidades do campo, quilombolas, indígenas, ciganas, idosa e da Educação Especial Inclusiva. (AUTOR, ANO, p. 93, grifo nosso).

15.11 Fortalecer, em regime de colaboração entre a União, Estado, Municípios e IES a formação inicial dos profissionais de instituições de Educação Básica, em todas as modalidades de ensino, promovendo a educação das relações étnico-raciais, o ensino de história e cultura afro-brasileira, africana, indígena e cigana, a educação das relações de gênero e diversidade sexual, dos direitos humanos e a educação do campo. (PARANÁ, 2015d, p. 93, grifo nosso).

É relevante mencionar que no texto final do PEE do Paraná, tais menções à palavra gênero foram substituídas por expressões como "combate à" ou "situação de" "discriminação, preconceito, violência" ou "todas as formas de discriminação" ou ainda "respeito entre homens e mulheres" (PARANÁ, 2015c). Além da palavra "gênero", foram retiradas do corpo do texto as expressões "diversidade sexual", "LGBT" e "sexualidade".

A leitura comparada dos dois documentos citados - a Constituição Federal de 1988 (BRASIL, 1988) e o documento-base para a elaboração do PEE do Paraná (PARANÁ, 2015d) - não permite uma percepção clara da contradição percebida pelas(os) deputadas(os) que acusaram a inconstitucionalidade do segundo documento. Apesar de o Deputado Pastor Edson Praczyk (PRB) afirmar: "sou contra a inserção da terminologia ideologia de gênero no Plano Estadual de Educação" (PARANÁ, 2015b, p. 10) e da deputada Cantora Mara Lima (PSDB) reforçar que "tenho que parabenizar a Deputada Claudia Pereira, [...] ao retirar o contido no anteprojeto que continha ideologia de gênero, que causou tanto confronto nas famílias no Estado do Paraná" (PARANÁ, 2015b), no projeto não havia menção ao termo "ideologia de gênero", nem mesmo algo que pudesse conectar gênero com família ou à sua destruição. Apenas a fala do deputado Professor Lemos (PT) foi na contramão desse discurso:

E no projeto de lei, desafio alguém a encontrar alguma contrariedade à família que foi instituída pela nossa Constituição Brasileira, não tem. Tem gente que fala sem ler, o projeto tem 100 páginas, é importante que todos leiam. Inclusive, àqueles que estão em casa - está no portal da Assembleia - leiam o projeto inteiro, não vão encontrar em nenhum lugar que o projeto alterou o conceito de família disposto na Constituição Brasileira, isto é mentira. Não está escrito em nenhum lugar do projeto. [Manifestações nas galerias - vaias] É bom ler o projeto inteiro. (PARANÁ, 2015b).

A indignação do deputado Professor Lemos (PT) deve-se ao fato de que, analisando a materialidade dos documentos a que deputadas(os) tiveram acesso, não havia incoerências ou incompatibilidades entre a legislação e o documento-base do PEE do Paraná. Entretanto, como afirma o deputado Gilson de Souza (PSC): "quando fala ideologia de gênero, alguns dizem que é algo tão simples, algo tão inofensivo que visa unicamente acabar com a discriminação nas escolas, e sabemos que não é isso" (PARANÁ, 2015a, p. 6). Assim, a interpretação que as/os parlamentares fizeram das referências ao "gênero" é baseada na crença de que existe um plano escuso por trás desta palavra, cujo objetivo é a destruição da família "tradicional", aquela composta por pai, mãe e filhos. Por isso é importante insistir que a "defesa" da Lei é a manobra utilizada para transformar uma pauta religiosa em pauta social.

O segundo argumento jurídico que parlamentares utilizaram é expresso na afirmação do direito que a família tem de educar as crianças da maneira como entendem que é o melhor para elas. 0 ponto central defendido neste raciocínio é que a escola deve "ensinar" (conteúdos) e a família, "educar". "Educação sexual", "valores" ou somente "educação" são expressões que aparecem nas falas de deputadas(os) para definir qual seria o papel da família. 0 deputado Paranhos (PSC) afirma: 
Gostaria que o Brasil estivesse discutindo um plano para melhorar a vida dos professores, para educar os nossos filhos. Educar os nossos filhos com o conhecimento, com o conhecimento, com a ciência, porque a família não pode empurrar o filho para que o professor eduque. A questão familiar tem que ser tocada pela família. (Aplausos) [...] 0 professor tem que ser valorizado para dar a disciplina e a educação, e a família tem que educar a família. (PARANÁ, 2015b).

As afirmações do deputado Paranhos (PSC) confundem a audiência, afinal discutir gênero exclui a possibilidade de discutir medidas "para melhorar a vida dos professores"? A inserção das questões de gênero na formação inicial das(os) professoras(es) - como previa a meta 15.11 do documento base do PEE do Paraná (PARANÁ, 2015d) -, por exemplo, significa que estas/estes poderiam ter melhores condições de lidar com as situações de violência de gênero na escola. Uma melhor formação não representaria melhoras em suas condições de trabalho? Além disso, é possível que professoras(es) se limitem a transmitir conteúdos? Nesse caso, como agir diante de tantas situações em que a desigualdade e a violência de gênero emergem?

Fernando Penna (2016) questiona a ideia de que a função de professoras(es) seja reduzida à instrução e a função da escola, consequentemente, se reduza à qualificação e socialização, assim como também postula o projeto de lei proposto pelo Movimento Escola Sem Partido (MESP). ${ }^{15}$ Isso porque, como o educador destaca, mesmo se a escola tentasse apenas instruir, no sentido estrito de qualificação profissional das(os) alunas(os), ela não deixaria de socializá-las(los). Esta socialização, por sua vez, ocorreria segundo certas representações e, dessa forma, estaria reduzindo o espaço para o desenvolvimento de diferentes subjetividades. Como consequência,

Impedir a problematização e pluralização de

15 Segundo o projeto original disposto no site do MESP, deveria ser fixado um cartaz em todas as salas de aula com seis "deveres do professor". 0 ítem 5, por exemplo, postula: "O Professor respeitará o direito dos pais a que seus filhos recebam a educação moral que esteja de acordo com suas próprias convicções." (ESCOLA SEM PARTIDO, 2020). representações segundo as quais os alunos estão sendo socializados é reforçar representações únicas, necessariamente excludentes e que reforçam desigualdades existentes na sociedade. Reduzir o espaço para que diferentes subjetividades se tornem possíveis constitui uma maneira de tentar controlar as subjetividades e formatá-las segundo um mesmo molde. Em suma, uma forma de embrutecimento de alunos e professores. (PENNA, 2016, p. 48).

A fala da deputada Cantora Mara Lima (PSDB) mostra como essa questão é muito mais sobre o desejo individual dos pais do que sobre a preocupação com as crianças:

Recebi e-mails de católicos, de evangélicos, de maçônicos, de muita gente, das famílias, de mães chorando dizendo: 'Eu prefiro deixar o meu filho dentro de casa e nunca mais ir para a escola e se tiver que outra pessoa ensinar o meu filho o que ele deve ser, os valores, sou eu quem vou dar ao meu filho.' (PARANÁ, 2015b).

O conflito entre interesse coletivo e interesse privado também é abordado por Penna (2016), afirmando que essa questão sobre "os valores, sou eu quem vou dar ao meu filho" é uma intenção que não se concretiza plenamente na realidade. De fato, a escola não tem o direito de obrigar alunas e alunos a mudar seus valores morais ou crenças religiosas, mas isso não significa que não se possa ao menos dialogar sobre esses temas. Como seria possível impedir que tantas crianças e/ou adolescentes que convivem, cada um com suas crenças e valores, expressem e debatam suas opiniões? Em casos de conflitos, preconceitos, deveria a/o professora(or) omitirse? Afinal, a escola ainda é um espaço de construção de valores que são fundamentais para a convivência democrática na sociedade. Portanto, Penna (2016, p. 53) afirma que:

0 interesse coletivo aqui está em combater uma forma de desigualdade arraigada na sociedade contemporânea, desconstruindo o ódio quanto a certas identidades de gênero. No entanto, interesses privados, de algumas famílias desejam proibir que os alunos da Educação Básica sequer entrem em contato com essas discussões, por irem contra suas convicções pessoais. 0 interesse coletivo de viver em uma sociedade 
mais igualitária é sobrepujado por vontades por vontades particulares de uma parcela dessa mesma sociedade.

Outra reflexão possível é sobre uma questão já exposta na fala do deputado Paranhos (PSC), quando diz que a "família tem que educar a família", e também aparece na fala do deputado Pastor Edson Praczyk (PRB):

É de foro íntimo, pessoal, intransferível da família a orientação, a educação sexual de distinção de sexo, de gênero ou tenha o nome que quiser. Depois de adultos, pós-fase escolar, acadêmica, aí a pessoa toma o rumo que quiser. Então, em defesa da família, da forma que creio, em defesa do direito do pai, da mãe, do avô, da avó, dos familiares ensinarem aos seus filhos, aos seus netos, é que sou contra a inserção da terminologia ideologia de gênero no Plano Estadual de Educação. (PARANÁ, 2015b).

A pesquisadora Guacira Lopes Louro (2011) argumenta que a ideia de que a educação sexual deve ser uma missão da família, e não da escola, está ancorada na visão de que a educação sexual deve passar por uma reflexão a respeito da moralidade e da religião. Ou seja, caso houvesse discussão sobre gênero e sexualidade nas escolas, ela seria necessariamente "tendenciosa". Dizer que outras formas de relacionamentos não heterossexuais são tão válidas quanto estas seria equivalente a estar fazendo "propaganda" LGBT. Segue a lógica de que se um assunto não é falado, logo, ele não existe. Louro (2011, p. 135, grifo do autor) ainda observa que:

A pressão desses grupos vai na direção do silenciamento, possivelmente supondo que se não se tocar nessas questões, elas não 'entrarão' na escola. Uma suposição que se revela impossível. As questões referentes à sexualidade estão, queira-se ou não, na escola. Elas fazem parte das conversas dos/as estudantes, elas estão nos grafites dos banheiros, nas piadas e brincadeiras, nas aproximações afetivas, nos namoros; e não apenas aí, elas estão também de fato nas salas de aula - assumidamente ou não -, nas falas e atitudes das professoras, dos professores e estudantes.

Portanto, não falar, literalmente, sobre sexo não significa que esse tema não esteja sendo ensinado de alguma forma. Como afirma Foucault (1988, p. 34), sobre os colégios do século XVIII, "pode-se ter a impressão de que aí, praticamente não se fala em sexo. Entretanto, basta atentar para os dispositivos arquitetônicos, para os regulamentos de disciplina e para toda a organização interior: lá se trata continuamente sobre sexo". A questão, assim sendo, é o que se ensina com o silenciamento do tema. Talvez, a reforçar os tabus que envolvem a sexualidade ou manter certos preconceitos no campo do aceitável. Além disso, se na escola, as professoras e professores, que são adultos preparados (idealmente) para abordar os temas sexualidade e gênero, não podem tratar desses assuntos, podemos perguntar se a família, ou se todas as famílias, estão cumprindo esse papel. Se estão, como elas estão abordando a educação sexual com suas/seus filhas(os)? E se não estão, com quem ou como as crianças estão aprendendo sobre sexualidade e gênero? São questões que indicam a urgência em trabalhar esses temas de maneira consistente e sistemática nas escolas.

\section{Considerações finais}

Este artigo pretendeu oferecer recursos para complexificar as análises da atuação de militantes religiosos, católicas(os) e evangélicas(os) na política brasileira. A recente cruzada contra tudo o que se refere a "gênero" influenciou na elaboração da legislação educacional dos últimos anos, através dos Planos de Educação aprovados em 2014 e 2015, e continua a ecoar em projetos de leis vinculados ao Movimento Escola Sem Partido. É, portanto, fundamental que esses temas estejam no centro das pesquisas na área da educação, para que se construam possibilidades de enfrentamento à violência, à exclusão e à evasão decorrentes desse tipo de discriminação.

Nesse sentido, ressalto que a defesa de uma suposta educação "neutra", que pressupõe o apagamento da pauta de gênero, implica também, como consequência, o apagamento das(os) sujeitas(os) que passam por estes 
processos de violência relacionados às suas identidades de gênero e/ou orientação sexual. A escola, como ambiente democrático e inclusivo, não pode estar ameaçada e coagida frente ao combate à exclusão.

\section{REFERÊNCIAS}

ALMEIDA, Ronaldo de. A onda quebrada evangélicos e conservadorismo. Cadernos Pagu [on-line], Campinas, SP, n. 50, 2017. Disponível em: https://www.scielo.br/scielo.php?script=sci_ arttext\&pid=S0104-83332017000200302\&lng=en \&nrm=iso\&tlng=pt. Acesso em: 11 jun. 2020.

ASSEMBLEIA LEGISLATIVA DO ESTADO DO PARANÁ (ALEP). Deputados. Perfil. Gilson de Souza. Disponível em: http://www.alep.pr.gov.br/ deputados/perfil/33-gilson-de-souza. Acesso em: 15 out. 2018.

ASSEMBLEIA LEGISLATIVA DO ESTADO DO PARANÁ (ALEP). Toda a tradição religiosa de Claudia Pereira está no "Fala Deputado" desta semana na Rádio Assembleia. ALEP, Curitiba, 02 dez. 2015. Disponível em: http://www.alep.pr.gov.br/divulgacao/noticias/ toda-a-tradicao-religiosa-de-claudia-pereiraesta-no-fala-deputado-desta-semana-na-radioassembleia. Acesso em: 15 out. 2018.

BRASIL. Presidência da República. Casa Civil. Constituição da República Federativa do Brasil de 1988. Brasília, DF, 1988. Disponível em: http:// www.planalto.gov.br/ccivil_03/constituicao/ constituicao.htm. Acesso em: 10 dez. 2018.

CASTRO, Roney Polato de. Diversidades sexuais e de gêneros no Plano Municipal de Educação de Juiz de Fora: breves apontamentos. Revista Pesquisa e Debate em Educação, Juiz de Fora, MG, v. 6, n. 2, p. 175-180, 2017.

CONFERÊNCIA EPISCOPAL PERUANA. La ideología de género: sus peligros y alcances. Agencia Católica de Informaciones, Lima, Peru, abr. 1998. Disponível em: https://www.aciprensa.com/controversias/ genero.htm. Acesso em: 25 mar. 2018.

CUNHA, Paulo José. A articulação das bancadas BBB. Congresso em Foco, Brasília, DF, 04 dez. 2017. Disponível em: https://congressoemfoco.uol.com. br/opiniao/colunas/a-articulacao-das-bancadasbbb/. Acesso em: 20 out. 2018.

DEPUTADA ESTADUAL CANTORA MARA LIMA. Mara Lima. Disponível em: http://www.deputadamaralima. com.br/mara.php. Acesso em: 15 out. 2018.
DIAS, Maria Berenice. Família homoafetiva. Bagoas - Estudos gays: gêneros e sexualidades, v. 2, n. 3, p. 39-63, 2009.

ESCOLA SEM PARTIDO. Deveres do professor. Disponível em: www.programaescolasempartido. org/faq. Acesso em: 11 jun. 2020.

FOUCAULT, Michel. História da sexualidade I: a vontade de saber. Tradução de Maria Thereza da Costa Albuquerque e J. A. Guilhon Albuquerque. Rio de Janeiro: Graal, 1988.

GIUMBELLI, Emerson Alessandro. 0 que é um ambiente laico?: espaços (inter) religiosos em instituições públicas. Cultura y Religión, Santiago, Chile, v. 7, n. 2, p. 32-47, 2013 a.

GIUMBELLI, Emerson Alessandro. Para estudar a laicidade, procure o religioso. In: GIUMBELLI, E; BELIVEAU, Veronica (org.). Religión, cultura y política en las sociedades del siglo XXI. Buenos Aires: Biblos, 2013b. p. 43-68.

JUNQUEIRA, Rogério Diniz. "Ideologia de gênero": a gênese de uma categoria política reacionária - ou: a promoção dos direitos humanos se tornou uma "ameaça à família natural"? In: RIBEIRO, Paula Regina Costa; MAGALHÃES, Joanalira Copes (org.). Debates contemporâneos sobre educação para a sexualidade. Rio Grande, RS: Editora da FURG, 2017. p. 25-52.

LOURO, Guacira Lopes. Gênero, sexualidade e educação: uma perspectiva pós-estruturalista. 12. ed. Petrópolis, RJ: Vozes, 2011.

LUNA, Naara. A criminalização da "ideologia de gênero": uma análise do debate sobre diversidade sexual na Câmara dos Deputados em 2015. Cadernos Pagu [on-line], Campinas, SP, v. 50, 2017. Disponível em: https://www.scielo.br/scielo.php?script=sci_ arttext\&pid=S0104-83332017000200311. Acesso em: 11 jun. 2020.

MIGUEL, Luis Felipe. Da "doutrinação marxista" à" ideologia de gênero" - Escola Sem Partido e as leis da mordaça no parlamento brasileiro. Revista Direito e Práxis, v. 7, n. 15, p. 590-621, 2016.

MINISTÉRIO DA EDUCAÇÃO. Nota Técnica no 24, de 17 de agosto de 2015. Brasília, DF: CGDH/ DPEDHUC/SECADI/MEC, 2015a. Disponível em: http://www.spm.gov.br/assuntos/conselho/notatecnica-no-24-conceito-genero-no-pne-mec.pdf. Acesso em: 17 nov. 2018.

MINISTÉRIO DA EDUCAÇÃO. Conselho Nacional de Educação. Nota Pública, de 01 de setembro de 2015. Brasília, DF, 2015b. Disponível em: http:// 
www.spm.gov.br/noticias/conselho-nacional-deeducacao-emite-nota-sobre-ideologia-de-genero-nosplanos-de-educacao/nota_publica_sobre_ideologia_ genero_01_09-1.pdf. Acesso em: 17 nov. 2018.

MONTERO, Paula. Controvérsias religiosas e esfera pública: repensando às religiões como discurso. Religião e Sociedade, Rio de Janeiro, v. 32, n. 1, p. 167-183, 2012.

NASSIF, Lourdes. Eleições 2018: Bancada evangélica cresce na Câmara e no Senado. Departamento Intersindical de Assessoria Parlamentar (DIAP), Brasília, DF, 28 nov. 2018. Disponível em: http://www.diap.org.br/index. php/noticias/noticias/28532-eleicoes-2018bancada-evangelica-cresce-na-camara-e-nosenado. Acesso em: 20 dez. 2018.

O'LEARY, Dale. The gender agenda: redefining equality. Lafayette, LA: Vital Issues Press, 1997.

PARANÁ. Sessão Ordinária do dia 17 de junho de 2015 - ata no 57. Diário Oficial da Assembleia. Poder Legislativo Estadual. Curitiba, edição 889, noㅡ 90, p. 3-8, 23 jun. 2015a. Disponível em: https:// www.documentos.dioe.pr.gov.br/dioe. Acesso em: 27 abr. 2018.

PARANÁ. Sessão Ordinária do dia 22 de junho de 2015 - ata no 58. Diário Oficial da Assembleia. Poder Legislativo Estadual. Curitiba, edição 891, noㅜ 92, p. 3-21, 25 jun. 2015b. Disponível em: https:// www.documentos.dioe.pr.gov.br/dioe. Acesso em: 27 abr. 2018.

PARANÁ. Assembleia Legislativa do Estado do Paraná. Lei no 18.492, de 24 de junho de 2015. Aprova o Plano Estadual de Educação do Paraná. Curitiba, 2015c. Disponível em: http://portal. alep.pr.gov.br/index.php/pesquisa-legislativa/ proposicao?idProposicao=55397. Acesso em: 11 jun. 2018.

PARANÁ. Comitê Gestor do Plano Estadual de Educação do Paraná. Documento Base: Plano Estadual de Educação do Paraná. Curitiba, 2015d. Disponível em: http://www.comunicacao. pr.gov.br/sites/default/arquivos_restritos/files / documento/2019-07/PEEPR_marcacoes.pdf. Acesso em: 11 jun. 2020.

PASTOR EDSON. Pastor Edson Praczyk. Disponível em: https://www.pastoredson.com.br/pastoredson-praczyk/. Acesso em: 15 out. 2018.

PENNA, Fernando de Araújo. Programa “Escola sem
Partido": uma ameaça à educação emancipadora. In: GABRIEL, Carmen Teresa; MONTEIRO, Ana Maria; MARTINS, Marcos Leonardo Bomfim (org.). Narrativas do Rio de Janeiro nas aulas de história. Rio de Janeiro: Mauad X, 2016. p. 43-58.

PIERUCCI, Antônio Flávio. Secularização em Max Weber: da contemporânea serventia de voltarmos a acessar aquele velho sentido. Revista Brasileira de Ciências Sociais, v 13, n. 37, p. 43-73, 1998.

RIBEIR0, Amanda; PÁTARO, Cristina Satiê de Oliveira; MEZZOMO, Frank Antonio. Religião e ideologia de gênero no Plano Nacional de Educação (PNE). Revista Relegens Thréskeia, v. 5, n. 2, p. 56-70, 2016.

SCALA, Jorge. La ideología del género o el género como herramienta de poder. Rosário, Argentina: Ediciones Logos Ar, 2010.

SILVA, Amanda da; CÉSAR, Maria Rita de Assis. A emergência da "ideologia de gênero" no discurso católico. InterMeio: Revista do Programa de PósGraduação em Educação, Campo Grande, MS, v. 23, n. 46, p. 193-213, 2017.

SOUZA, Sandra Duarte de. Entre o diverso e o controverso: direitos LGBT e atuação de deputados e deputadas federais das bancadas católica e evangélica. In: FERRARI, Anderson; CASTRO, Roney Polato de (org.). Diversidades sexuais e de gêneros: desafios e potencialidades de um campo de pesquisa e conhecimento. Campinas, SP: Pontes, 2017. p. 51-73.

VARGAS, Myriam Aldana; CAVAGNOLI, Murilo; CATTANI, Daian. Relações de gênero ou ideologia de gênero? (Im)possibilidades democráticas no debate (a)político sobre o plano municipal de educação de Chapecó (SC). Revista Fórum Identidades, v. 22, n. 22, p. 234-250, jan./abr. 2016.

VEIGA, João Marcos. Entidades reagem a tentativa de exclusão de questões que abordam "gênero" e "sexualidade" Planos de Educação. Associação Nacional de Pós-Graduação e Pesquisa em Educação (ANPEd), Rio de Janeiro, 26 jun. 2015. Disponível em: http://www.anped.org.br/news/ entidades-reagem-tentativa-de-exclusao-dequestoes-que-abordam-genero-e-sexualidade-nosplanos. Acesso em: 17 nov. 2018.

Recebido em: 22/02/2020

Aprovado em: 29/05/2020

(cc) BYY-NC Este é um artigo publicado em acesso aberto sob uma licença Creative Commons. 